\title{
ELECTRON MICROSCOPY OF CAMPYLOBACTER JEJUNI
}

\author{
P. J. PeAD \\ Department of Virology, Public Health Laboratory, St Mary's Hospital, Portsmouth, \\ Hampshire PO3 $6 A Q$
}

\section{Plates XXXII-XXXIV}

THE first detailed description of the appearance of Vibrio fetus in stained smears was given by Smith and Taylor (1919). More recently, the electron microscope has been used for the study of shadow-cast preparations (Rhoades, 1954) and ultrathin sections (Werner, Levy and Spurlock, 1961; Werner, 1963). Studies by several techniques were described by Ritchie, Keeler and Bryner (1966). After the description of microaerophilic vibrios in association with human gastroenteritis (Vinzent, Dumas and Picard, 1947), the organism has been reclassified as a Campylobacter (Véron and Chatelain, 1973; Smibert, 1974). Strains of Campylobacter jejuni isolated from patients with gastroenteritis differ from animal strains of $V$. fetus in possessing a higher optimum growth temperature, $43^{\circ} \mathrm{C}$, and bile tolerance. More recently, selective techniques (Butzler et al., 1973; Skirrow, 1977) have enabled diagnostic laboratories to attempt routine isolation of the organism. This report describes morphological findings from the electronmicroscopic study of some strains of $C$. jejuni isolated from human patients.

\section{MATERIALS AND METHODS}

Isolation and identification of organisms. Liquid stools from 56 patients with acute gastroenteritis were cultured by the selective method described by Skirrow (1977). Colonies were subcultured on MacConkey agar, nutrient agar enriched with horse blood $10 \%(\mathrm{v} / \mathrm{v})$, and salt broth. Isolates were provisionally identified by gram-staining reaction, motility, oxidase reaction, catalase production and antibiotic-sensitivity pattern. Confirmatory tests included $\mathrm{H}_{2} \mathrm{~S}$ production, 2, 3, 5-triphenyltetrazolium chloride tolerance, sensitivity to metronidazole and inhibition by nalidixic acid.

Electronmicroscopy. Organisms were removed from culture media and emulsified in phosphate-buffered saline (Oxoid). A small quantity of the suspension was diluted in distilled water containing a trace of bovine serum albumin and was then mixed with an aqueous solution of potassium phosphotungstate $1 \%(\mathrm{w} / \mathrm{v})$ at $p \mathrm{H} 6 \cdot 5$. This negatively stained preparation was applied to a formvar-carbon grid of 400 mesh and examined in an AEI Corinth 500 electron microscope. In addition, some cultures were examined after prolonged incubation.

\section{RESULTS}

There were five isolations of $C$. jejuni from the 56 stools. Morphologically, all strains were very similar. In the negatively stained preparations most cells were S-shaped or elongated spirals (fig. 1), resembling some Spirillum spp., and were 1.4-3.0 $\mu \mathrm{m}$ long and 0.4-0.6 $\mu \mathrm{m}$ wide. A few comma-shaped organisms were seen. Some paired organisms were seen in tandem, presumably undergoing division, but longer chains of organisms were net observed. Round "coccoidal" forms $0.6-1.2 \mu \mathrm{m}$ in diameter were also seen (fig. 2).

Numerous globular extrusions of the cell wall (fig. 3) were seen in preparations of each form of the organism. The cytoplasmic membrane was slightly uneven in outline but did not display extrusions, and in most cases was smoothly contoured, forming the basic shape of the organism

Received 4 Dec. 1978; accepted 9 Jan. 1979.

J. MED. MKROBIOL. --VOL. 12 (1979) 
(fig. 3). This membrane appeared to be convoluted in some organisms, probably due to retraction within the cell wall (fig. 4). The cytoplasm was seen as a compact matrix and in some organisms the only discernable feature was the mottled surface effect of the cytoplasmic contents. Occasionally the cytoplasm was seen to be traversed by dark-staining clefts (fig. 4). Disc-shaped electron-dense inclusions measuring $95-155 \mathrm{~nm}$ were seen in some of the $S$-shaped organisms (fig. 4).

Most organisms possessed bipolar flagella; some had a single polar flagellum but non-flagellate forms were rarely seen. The flagellar length ranged from 2.6 to $3.9 \mu \mathrm{m}$ and the diameter averaged $21 \mathrm{~nm}$. A parallel linear substructure was visible, but a flagellar sheath was not evident (fig. 5). The site of flagellar attachment to the organisms was usually within a concave depression (fig. 6). Frequently, a prominent electron-lucid rim was visible at the periphery of the depression. Closer examination of the site of attachment in partially autolysed organisms showed the flagellum fastened to thickened areas of the cell wall and cytoplasmic membrane.

Prolonged incubation of the cultures resulted in an increase in the number of coccoidal forms; after incubation for $72 \mathrm{~h}$, at least $50 \%$ of the observed bacterial population consisted of coccoidal forms.

\section{Discussion}

Examination of the five strains of $C$. jejuni isolated from humans demonstrated a close morphological similarity to $V$. fetus of veterinary origin as described by Ritchie et al. (1966). These authors also observed cell-wall extrusions, cytoplasmic clefts and electron-dense intracytoplasmic inclusions in sectioned and unfixed whole-cell preparations. Electron-dense inclusions have also been reported by others (Werner et al., 1961; Werner, 1963) in sectioned organisms. No large terminal bodies or lamellar bodies as described by Ritchie et al. (1966) were seen in the present study. Most of the cells in the preparations possessed bipolar flagella. Some accounts have reported a unipolar distribution in V. fetus as more common (Smith and Taylor, 1919; Rhoades, 1954; Véron and Chatelain, 1973). Flagellar size and ultrastructure noted in the present study closely resembled that of $C$. fetus described by McCoy $e$ t al. (1975). The mode of flagellar attachment in $C$. jejuni was very similar to that demonstrated in vibrios by Vaituzis and Doetsch (1969). The increase in coccoidal morphology during prolonged incubation is presumed to be associated with a decrease of available nutrient.

\section{SUMMARY}

Stools from 56 patients with gastroenteritis were cultured for Campylobacter jejuni. The five strains isolated were examined by electron microscopy. The campylobacter cells were pleomorphic and most displayed appearances similar to those of $V$. fetus. Morphological changes were observed in cultures subjected to prolonged incubation.

I would like to thank Dr S. A. Rousseau and Dr A. K. Chaudhuri for supplying cultures and Dr A. A. Saeed and Miss S. I. Hayter for their help in the preparation of the manuscript.

\section{REFERENCES}

Butzler, J. P., Dekeyser, P., Detrain, M. and Dehaen, F. 1973. Related vibrio in stools. $J$. Pediat., 82, 493.

McCoy, E. C., Doyle, D., Wiltberger, H., Burda, K. And Winter, A. J. 1975. Flagellar ultrastructure and flagella-associated antigens of Campylobacter fetus. J. Bact., 122, 307.

RHOADEs, H. E. 1954. The illustration of the morphology of Vibrio fetus by electron microscopy. Am. J. vet. Res., 15, 630.

RItCHIE, A. E., KeELER, R. F. AND BRyner. J. H. 1966. Anatomical features of Vibrio fetus: electron microscopic survey. J. gen. Microbiol., 43, 427.

SKIRRow, M. B. 1977. Campylobacter enteritis; a "new" disease. Brit. med. J., 2, 9.

SMIBERT, R. M. 1974. Campylobacter. In Bergey's manual of determinative bacteriology, 8th ed., edited by R. E. Buchanan and N. E. Gibbons, Baltimore, p. 207. 
EleCtron MicrosCopy OF CAMPYLOBACTER

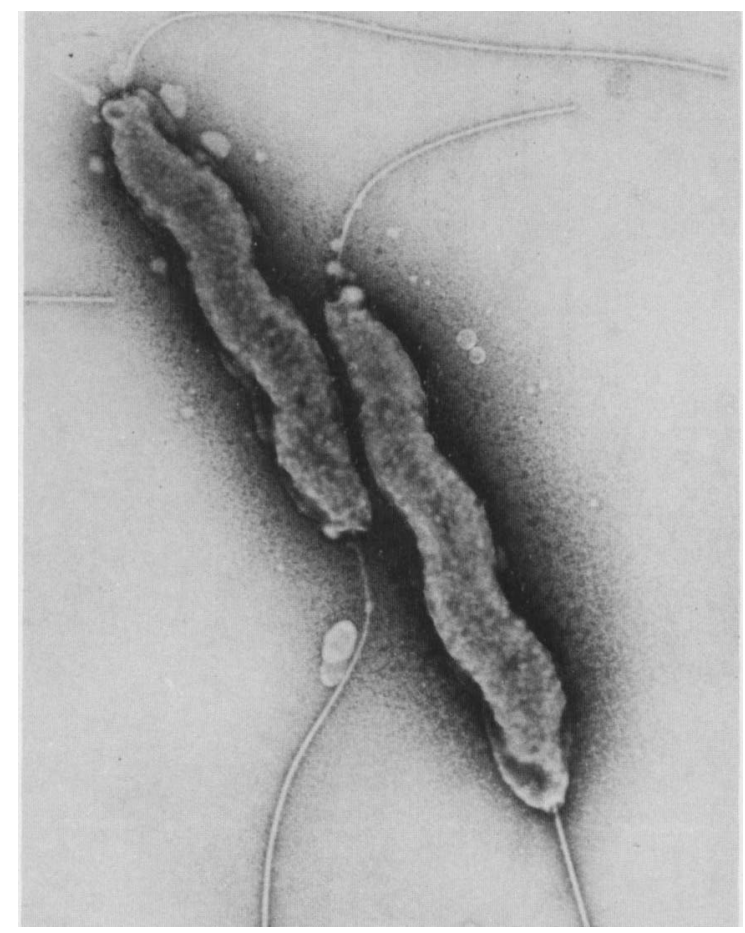

FIG. 1.-Elongated spiral forms of Campylobacter jejuni, typical of the majority of organisms seen. $\times 20222$.

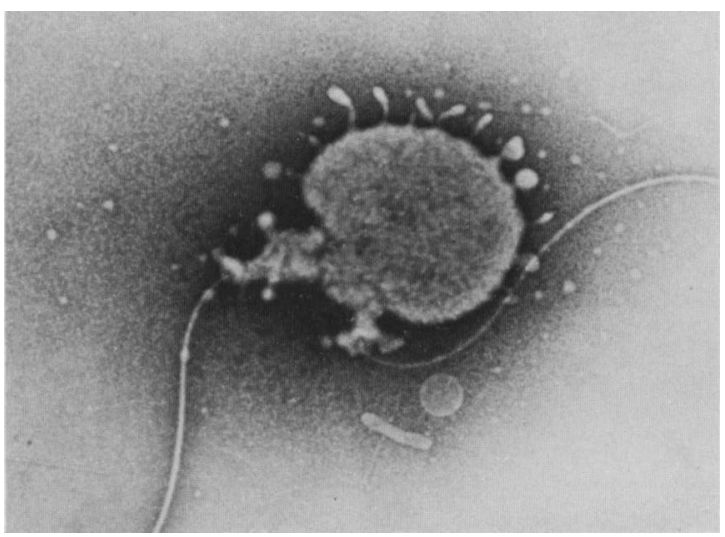

FIG. 2.-Rounded, coccoidal forms of Campylobacter jejuni. $\times 20222$. 
PeAD

ELECTRON MiCROSCOPY OF CAMPYLOBACTER

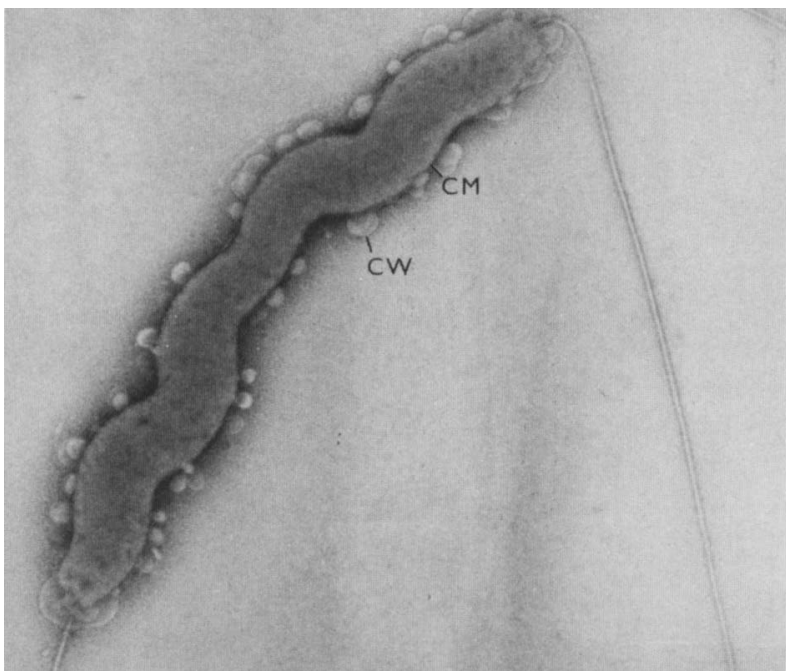

FIG. 3.-An organism showing multiple globular extrusions of the cell wall $(\mathrm{CW}) . \mathrm{CM}=$ cytoplasmic membrane. $\times 20222$.

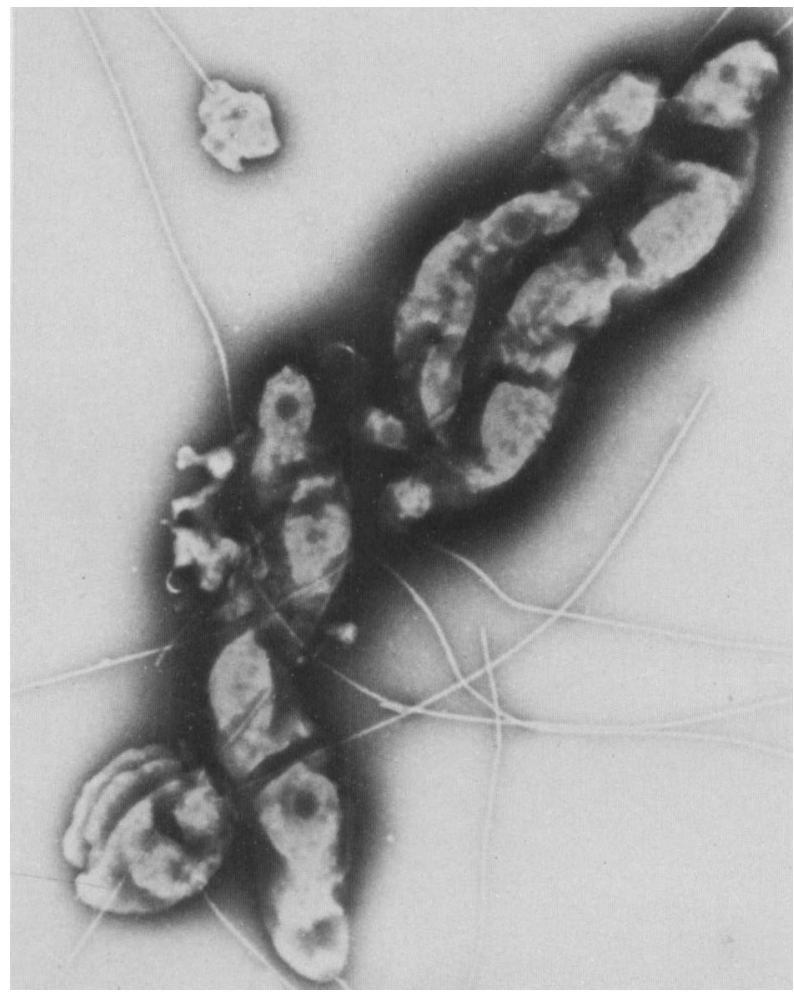

FIG. 4.-Organisms displaying distorted and retracted cytoplasm with dark-staining transverse clefts. Several round electron-dense inclusions are also visible. $\times 20222$. 


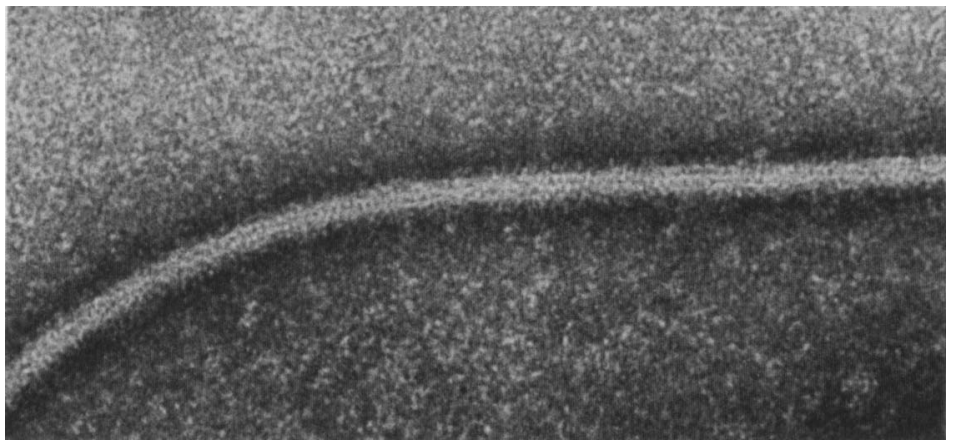

Fig. 5.-Portion of a flagellum showing the parallel linear substructure. There is no evidence of a flagellar sheath. $\times 151392$.

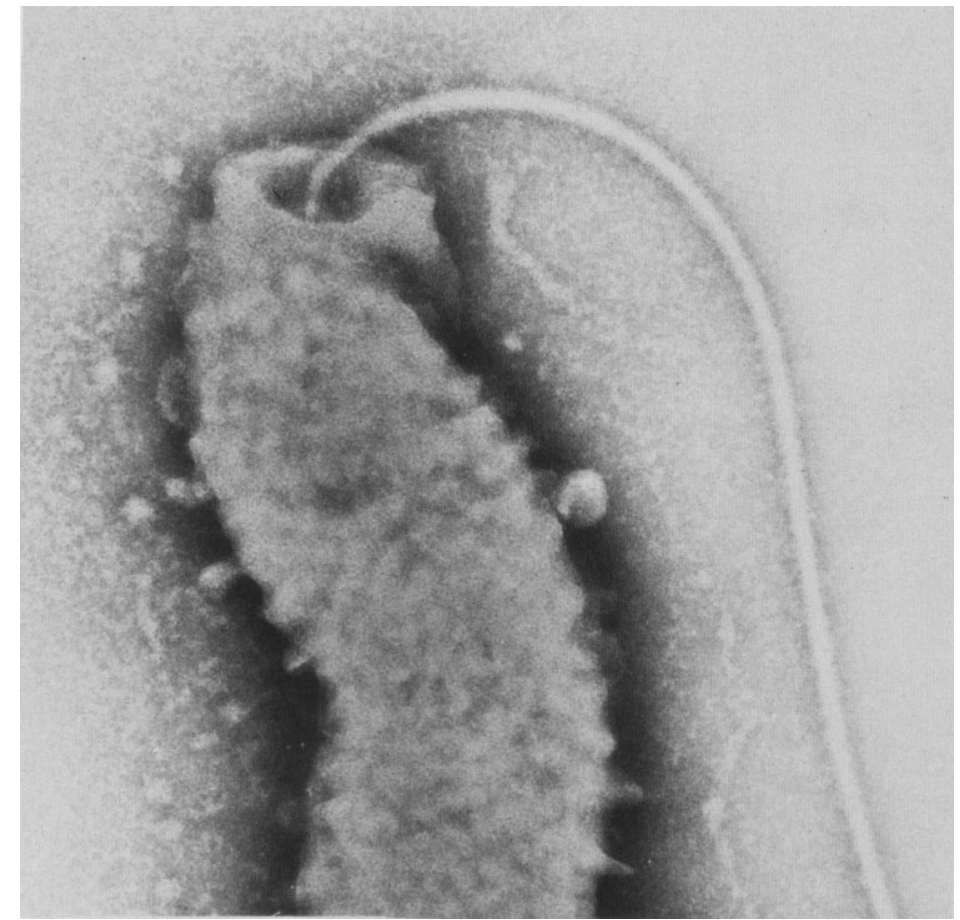

Fig. 6. - Site of flagellar attachment within a concave depression of the polar cell wall. $\times 75696$. 
SMITH, T. AND TAYLOR, M. S. 1919. Some morphological and biological characters of the Spirilla (Vibrio fetus $\mathrm{n} . \mathrm{sp}$.) associated with disease of the fetal membranes in cattle. J. exp. Med., 30, 299.

V AITUZIS, Z. AND DoETSCH, R. N. 1969. Relationship between cell wall cytoplasmic membrane and bacterial motility. J. Bact., 100, 512.

VéRon, M. AND Chatelain, R. 1973. Taxonomic study of the genus Campylobacter Sebald and Véron and designation of the neotype strain for the type species, Campylobacter fetus (Smith and Taylor) Sebald and Véron. Int. J. syst. Bact., 23, 122.

VinZENT, R., DumAS. J. AND PICARD, N. 1947. Septicémie grave en cours de la grosses, due à un vibrion; Avortement consecutif. Bull. Acad. natn. Méd., 131, 90.

WERNER, H. J. 1963. Further electron microscopic observations of a strain of Vibrio fetus. Am. J. vet. Res., 24, 881.

Werner, H. J., LeVy, H. AND SPURLOCK, B. O. 1961. Electron microscopic observations of a mucoid strain of Vibrio fetus. Am. J. vet. Res., 22, 1121. 